\title{
Article
}

\section{Analysis of the behaviour of rocks under cyclic loads}

\author{
Marilena Cardu ${ }^{1,2 *}$, Simone Saltarin ${ }^{1,2}$ and Carmine Todaro ${ }^{2}$ \\ 1 Department of Environment, Land and Infrastructure Engineering-DIATI, Politecnico di Torino, Italy \\ 2 National Research Council, Geosciences and Georesources Institute-IGG, Politecnico di Torino, Italy \\ * Correspondence: marilena.cardu@polito.it
}

\begin{abstract}
The cyclic load applied to civil and mining structures can lead to a reduction of the materials' strength, different from that which would occur with a monotonous load. Numerous cases can be found where the decay of the rock parameters subjected to this type of stress leads to progressive or sudden collapse: among them, tunnel walls, pillars and slabs in mining operations, roads with a heavy vehicle transit, abutments of bridges and dams can be quoted. The topic can therefore be fundamental for a correct structural design, to avoid problems during the life of the structure. However, given the heterogeneity of the rock materials and the difficulty of their characterization under this aspect, an unequivocal analysis is hardly achievable. Then, the discussion initially develops through a general historical review of the concept of fatigue, with a synthetic collection of case histories. The laboratory tests on rock samples are then examined and the most important results obtained are discussed. Finally, a comparison between different types of tests is proposed. The experimental data are expressed through the Wöhler diagram. The goal is to fill the lack of design codes or standards in the field of cyclic stresses applied to rock materials, the understanding of its effect being of great interest in order to apply suitable parameters in the design phase.
\end{abstract}

Keywords: cyclic loads, fatigue of rocks, S/N curves, number of cycles, stress-strain behaviour.

\section{Introduction}

A cyclic load is known to cause a material to fail at a stress level below its resistance under static loading [1]. This phenomenon was called "fatigue" by Poncelet in 1839 [2], but the one who developed first a systematic research on this topic was the German railway engineer Wöhler [2,3] who, around 1870, presented a series of important studies on the basis of which he deduced that the mechanical and elastic characteristics of some metallic materials, determined with ordinary static tests, were not sufficient to explain their behavior in the conditions in which the effort was repeated "a sufficient number of times": he proved to be false the concept, until then considered universally valid, according to which it was believed that, if the material had been stressed below its elasticity limit, it would resist indefinitely: this could only be valid when the stress was kept in the static field. Wöhler had discovered a still unknown property of cyclic loads, indeed of the cyclic nature of the load, without any clarification about the type of stress: the importance was in its repetition; it was therefore fundamental, for the study of the phenomenon, to investigate the nature of the fracture and the nature of the efforts that induced it. A chapter closes with Wöhler, who was the first to deal systematically with the problem of material fatigue and to develop a method and terminology (both still in use) to describe it quantitatively. The following chapters are too many, and too diversified, to be examined in this context, but Bauschinger (quoted by [4]) cannot fail to be quoted: towards the end of the nineteenth century, he experimentally examined the phenomena of mechanical hysteresis and revised the concept of "elastic limit": his conclusion, certainly simplified, is that the fatigue limit is nothing more than the true elastic limit. The cyclic load, if repeated many times, amplifies and brings out those deviations from the elastic behavior that are too small to be observed directly and which are not taken into account in defining the conventional elastic limit. In this regard, it is useful to quote [5]: "Bauschinger, working before 
the time of the metallographic microscope, naturally placed emphasis on considering the elastic limit as the main factor in determining the fatigue strength. Later, the idea of fatigue failure was consolidated as a result of an expanding fracture".

The phenomenon was approached to rocks only in the second half of the twentieth century, initially with rather limited studies, and only from 1970 with more in-depth theoretical and experimental research [6-15]. The heterogeneity of the research in the literature makes it difficult to unify through a single analytical theorizing of fatigue failure: different authors often reach different conclusions [16-19].

According to [20, 21, 7], fatigue failure occurs under a cyclic amplitude stress that would not cause failure if applied only once. The fact that a material breaks after a certain number of cycles indicates that a permanent change must occur with each cycle [22]. Each cycle must therefore produce a certain plastic strain, even if very small.

There are many and very diversified cases in which a rock structure, during its service life, is subjected to cyclic loads: some examples of recurrent phenomena to which stone materials are subjected and in which it can be important, theoretically or practically, the deepening of the knowledge of the behavior under cyclic loads are:

- vibrations induced by seismic events;

- decay of the rock on site following the repeated action of shock waves due to excavation with explosives;

- natural supports in mines (pillars, slabs) subjected to load variations (cyclical or aperiodic, however repeated) connected with the exploitation activity;

- use of stone structural elements subjected to cyclic loads imposed by particularities of their use (e.g. bridge structures, basements of vibrating machines);

- $\quad$ similar phenomena deriving from repeated stresses caused by the transit of vehicles;

- use of particular stone elements subjected to cyclic thermal excursions and consequent stresses;

- demolition with impact hammers or other mechanical equipment acting through repeated impacts;

- crushing, drilling and other operations on rock materials carried out with equipment that exploit the effect of vibrations;

- comminution of rocks carried out with repeated impact machines or cyclically variable compressive stresses.

\section{Strength and time}

The study of the mechanical behavior of rocks and, in particular, of that stretch of behavior which is the failure, is usually conducted in a one-dimensional way, in the meaning that it is sometimes enough to indicate a load at which the material yields. The "time" factor is usually neglected; yet, in everyday conversation, the adjective "strong" is used to say that something lasts a long time in service, rather than to say that the breakage requires a considerable effort. It is therefore useful to move from a description of type 1 to one of type 2, two-dimensional (Figure 1). 


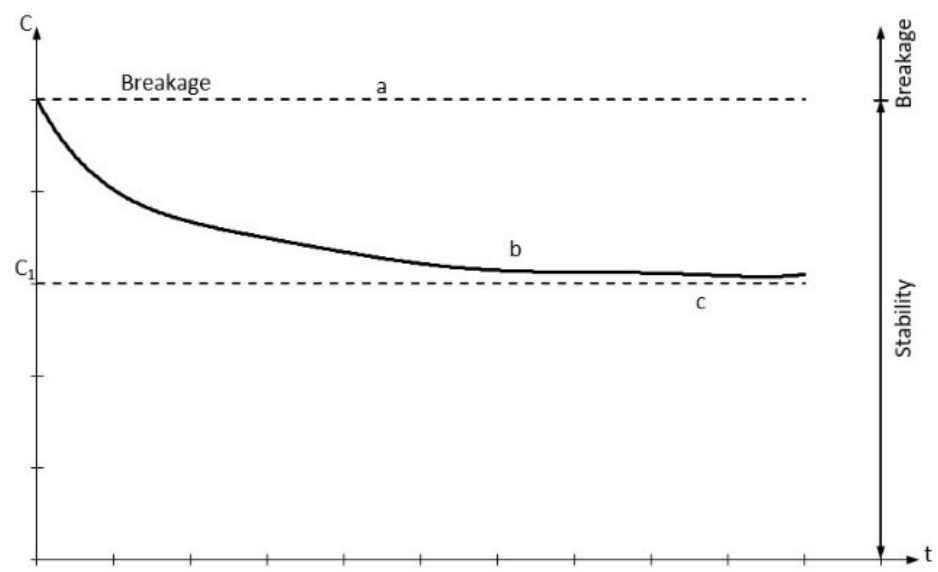

Figure 1. From the simple representation of the two states (stability-breakage) separated by a defined load level, one can move on to the representation on the load-time plane, which highlights three possibilities: a) unfailingly yielding occurs; b) there may be stability or failure, and the occurrence of one or the other eventuality is a function of time; c) there is unfailingly stability.

It is known that a load (in very general meaning) that is tolerable in the short term can be dangerous in the long term. The curve is generally given a plausible and simple analytical expression, such as:

$$
\log (\mathrm{c}-\mathrm{C} 1)=\mathrm{A}-\mathrm{B} \log \mathrm{t}
$$

where $\mathrm{c}$ is the load, $\mathrm{c} 1$ is a hypothetical load low enough to be considered indefinitely tolerable. This expression has no deep meaning: it is convenient, it allows to describe the material with only three parameters and, in general, it is flexible enough to be able to reliably reproduce the experimental data. A logarithmic scale is generally used on the time axis, as the time scales can be very different.

The existence of "different times" means that introducing the "time" parameter in the description brings with it a considerable practical difficulty: it is difficult to deduce, from what has been measured on a decimetric specimen, the behavior of a much larger structure, but deducing from what has been found in a test lasting minutes or, at most, days, what will happen to the material over the course of years or decades is even more difficult. Time seems incompressible, but something has been done and can still be done (accelerated tests and so on). Furthermore, time exacerbates another problem: in fact, it is the dimension in which the case acts: just think that time, regardless of its simple flow, is marked by events, not all known, not all knowable and not all rigidly determined by the previous ones: time is the measure of what happens in it. The case has its role, of course, even in ordinary mechanical tests, but in a time-based strength test this role is enhanced: it is necessary to abandon the idea of giving, for the same material, a "tolerable load-time" relationship and move instead to a functional link "load-probability of survival-time". Considering the behavior of a population of samples of a certain material, three cases can be hypothesized:

1. under the same load conditions, all individuals behave in the same way, gradually wither away according to the same law and die at the same instant. The chance has no role, everything is determined and knowable and the survival curve has the trend shown in Figure 2 (case 1): total survival up to T, total mortality over T;

2. always under the same load conditions, only the chance acts, so that an equal percentage of the population dies, on average, in the same range: this is the case, for example, of the radioactive decay of an element, a totally random phenomenon. The survival curve is, then, the negative exponential shown in Figure 2 (case 2); 


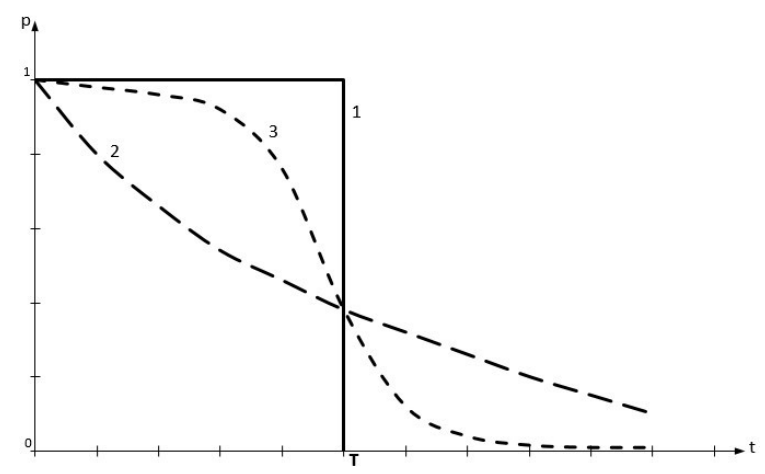

Figure 2. The possible trends over time of the probability of survival at a certain load level can describe: a perfectly determined behavior (case 1); a purely determined by chance behavior (case 2); a behavior that is only partially dominated by chance (case 3), one of the many possible Weibull distributions; this type of curve degenerates into 1 for $\mathrm{k}_{2} \rightarrow \infty$, into 2 for $\mathrm{k}_{2} \rightarrow 1$.

3. However, the survival distributions over time that are actually observed have intermediate trends (for example, that of Figure 2, case 3): chance plays a role, but it is not paramount. These survival distributions can have very different trends: a distribution that represents them well is that of [23]:

$$
\mathrm{P}=\mathrm{e}^{-(\mathrm{t} / \mathrm{k} 1)^{\mathrm{k} 2}}
$$

where $\mathrm{P}$ is the probability of survival. Again, the reason for the success of the function is essentially practical: it describes the situation with only two parameters and is flexible enough to agree with most of the experimentally found distributions. Simple: but the description of the material, which was a number and then became a curve in the load-time plane, now becomes a surface in the load-time-probability of survival space.

\section{The cyclic loads}

All resistant materials, during their life, are subjected to both constant and variable stresses over time. The laboratory tests try to reproduce, in a simplified but as significant as possible way, the real behavior: they must therefore allow the reference to characteristic properties of the materials: the difference in behavior that is found under constant loads and under variable loads applied repeatedly requires at least two types of tests: static tests and cyclic tests. In the two experimental conditions, the trend of stresses as a function of time is represented by a constant stress line or by a cyclic function, if the event is repeated on a regular basis (if the frequency is irregular, the proportionality can be found statistically). The result of the test is expressed through the number of cycles at which, due to predetermined values of the other parameters, which are kept fixed during the test, failure occurs. Based on the different frequencies of cyclic loading, fatigue can be classified as follows [24]:

- $\quad$ High frequency $(\mathrm{f}>10 \mathrm{~Hz})$;

- $\quad$ Medium frequency $(10 \mathrm{~Hz}>\mathrm{f}>0,1 \mathrm{~Hz})$;

- $\quad$ Low frequency $(\mathrm{f}<0,1 \mathrm{~Hz})$;

- Static (constant load).

The most common tests are those at a frequency of 1-2 Hz. According to some researchers [25-27] there is no clear trend linking the load frequency to fatigue life at high load frequencies.

[28] attributed a direct relationship between load frequency, fatigue strength and fatigue life at low frequencies (usually less than $1 \mathrm{~Hz}$ ). The load is generally applied by uniaxial compression, but there are examples of applications by shear, bending or tensile stresses [29]. 
With regard to rocks, some experimental values taken from the literature, after normalization (expression of the stress as a fraction of the breaking load), are collected in Figure 3 [30-41, 28] from cyclic compression tests: the distribution is rather dispersed, it is probably of an exponential type and has an asymptote corresponding to a stress level equal to a fraction of the static strength, which can be roughly identified with the "fatigue limit" of the rock material, a value below which the material resists indefinitely.

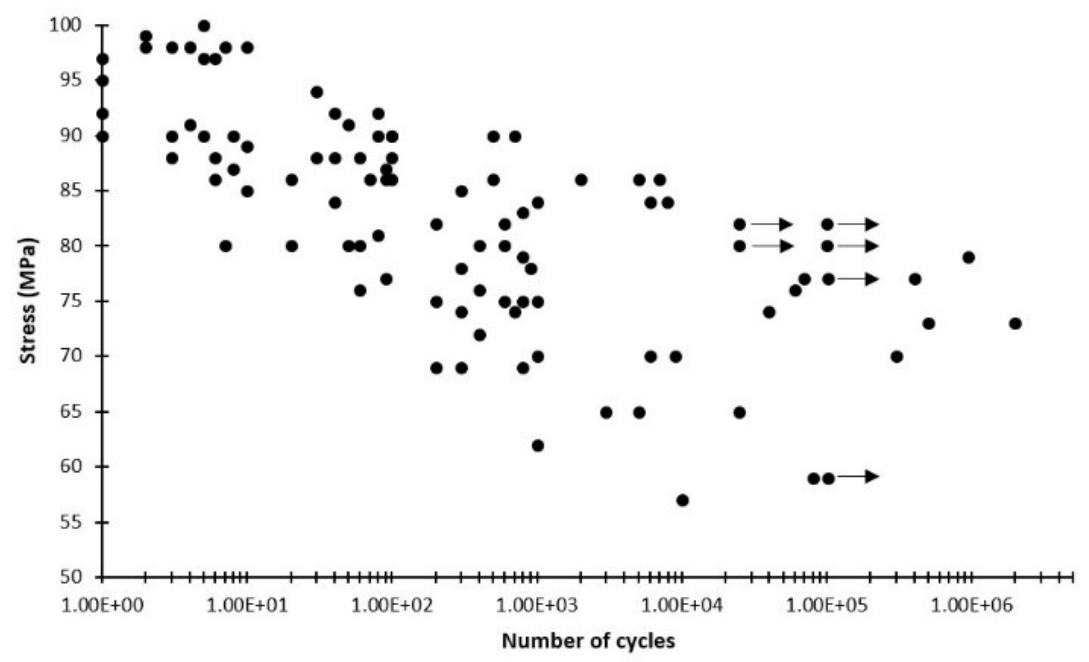

Figure 3. Representation, in the $\mathrm{S} / \mathrm{N}$ plane (stress causing failure / corresponding number of cycles), of the experimental values found in literature on different rocks. The arrows show the data relating to the specimens where failure did not occur (corresponding to the number of cycles shown in the horizontal axis).

The interest in the study of rock fatigue can be traced back, in addition to application purposes, to a theoretical research: in fact, while in artificial materials in general there is an excellent constancy of mechanical behavior, this does not happen in rocks, although they come from the same orebody and are apparently identical: this difference is, at least in part, to be attributed to the fact that artificial materials do not have a "mechanical history", while rocks always have a long and little known history (both geological, natural , and industrial, which takes place starting from the extraction phases up to the subsequent processing phases), where cyclic loads repeated a large number of times have certainly had considerable weight. The study of these phenomena in the laboratory, under obviously simplified conditions with respect to historical reality, but for this reason susceptible to control and rational interpretation, can therefore show some ways to quantitatively characterize this variability. Furthermore, the study can be useful for a better understanding of the phenomena of local plasticization and breaking of rock materials, knowledge that is difficult to obtain without resorting to repeated cyclic loading conditions.

In the study of rock fatigue, terms and methodologies are borrowed from the homonymous study of artificial materials, especially metals, but this can't be done uncritically: not only the term "rock materials" cover a wider and more diversified variety than that of artificial materials but, also conceptually, the word "material" is used with different meaning in the two contexts: an artificial material is made to exhibit given properties and behaviours that are part of its definition; a rock is defined by a certain geological context, by a geographical area, and it has ranges of composition, structure, mechanical behavior, etc., which are not part of the definition. Therefore, the same normalized $\mathrm{S} / \mathrm{N}$ curve can result from test campaigns on a granite, a marble, a sandstone, without this implying that the phenomenon of fatigue is the same in the three cases. Furthermore, in the case of artificial materials it can be assumed that what was deduced from a test on a specimen is correlated to what could have been deduced from another test on the same sample under different 
conditions: in fact, there is a lot of specimens that can be considered "mechanical twins", so it is sufficient to carry out the test under different conditions on another specimen of the lot. In the case of rocks, on the contrary, the lot of specimens is a population of individuals vaguely related to each other, but individually characterized by (relevant) details of composition, structure, etc., and by personal stories that are the local reflection of history, geological or post-geological, of the body from which they were taken. Despite the visual homogeneity, it is not possible, not even based on non-destructive tests performed test by test, to select a population of twins, nor would it make sense to do so, if the result must then be referred to that specific material. Rather, it is necessary to accept the dispersion of the results as a result, and find an adequate statistical representation. In this meaning, two possibilities arise: to use the dispersed results to describe the behavior of a hypothetical average material, for example by means of a $\mathrm{S} / \mathrm{N}$ relation referring to this abstract entity, of which some properties can be postulated, or to use them to describe the material in terms of survival probability at different numbers of cycles and for different stresses. Technically, the two approaches differ only in that the first places emphasis on the average values, the second on the median values of the fatigue life; in practice, however, it was found that the latter allows a more plausible and less uncertain interpretation of the experimental results.

\subsection{Experimental equipment}

A program-controlled MTS rigid press was used to conduct the tests. The device allows the possibility of programming according to the desired law of load variation. In the tests described below, a sinusoidal law with a frequency of $2 \mathrm{~Hz}$ was adopted, on the basis of extensive preliminary tests aimed at optimizing the accuracy obtainable at aiven load; the maximum frequency limit compatible with adequate operation is however $5 \mathrm{~Hz}$, without being bound to the sinusoidal shape; the maximum applicable load is equal to 2.7 $\mathrm{MN}$ and this has allowed the press to be used in conditions sufficiently far from extreme performance; the self-regulation of the press takes place promptly $(0.1 \mathrm{~ms})$; the test parameters are acquired continuously and the accuracy is very high compared to the full scale values; the stiffness $(134 \times 108 \mathrm{~N} / \mathrm{m})$ is considerably greater than that of ordinary presses: this feature allows the machine to be used also for the study of post-breaking behavior and, in carrying out fatigue tests, it represents a guarantee of faithful reproduction of the desired cycle until the end of the test. During the tests, the load ranged between a minimum value $(40 \mathrm{kN})$ and a maximum, established from test to test, until failure, or the achievement of 106 cycles. The same machine also performed the preliminary characterization tests of the experimental material and the hysteresis tests with increasing load, which allowed to investigate the deviations from the elastic behavior of the material.

\subsection{The experimental material}

The material was provided by a coring campaign carried out in limestone, on which the following characteristics were obtained: average content in $\mathrm{CaCO}_{3}=94.7 \%$, insoluble residue essentially consisting of quartz with a crystalline grain between 30 and $100 \mu \mathrm{m}$ and recrystallized veins with coarser grain. Knoop micro-hardness tests were carried out on some polished sections, which gave average values between 1285 and $1530 \mathrm{MPa}$, with deviations between $7.14 \%$ and $18.68 \%$. The material is micro-mechanically quite homogeneous and visually homogeneous. For the purposes of the tests, 62 cylindrical specimens with dimensions $143 \times 71 \mathrm{~mm}$ and 20 with dimensions $110 \times 55 \mathrm{~mm}$ were obtained. All specimens were subjected to non-destructive tests, consisting in the determination of the ultrasound transmission speed $\mathrm{V}$ and water absorption I: rather dispersed values have been obtained for both ( $V=4500-6500 \mathrm{~m} / \mathrm{s} ; \mathrm{I}=0,0001-0.0009$, without any correlation with visually observable characteristics). 26 of the 82 available specimens (16 with $71 \mathrm{~mm}$ diameter and 10 with $55 \mathrm{~mm}$ diameter) were used for destructive tests to 
determine the uniaxial compressive strength (UCS) and the elastic modulus. The compressive strength tests were carried out in two ways: with the load application speed established by the ISRM standards [42] ("static" tests) and with a much higher speed, approximately corresponding to that used in the fatigue tests (indicated below as "dynamics"). Considerably dispersed values were obtained for all the mechanical and elastic characteristics, however suitable for defining average values, collected in Table 1.

Table 1. Average values obtained from the determination of the mechanical and elastic characteristics of the samples.

\begin{tabular}{cc}
\hline Characteristic & Average value \\
\hline UCS, $\varnothing 71 \mathrm{~mm}$, static & $73.5 \mathrm{MPa}$ \\
$\mathrm{UCS}, \varnothing 71 \mathrm{~mm}$, dynamic & $108 \mathrm{MPa}$ \\
$\mathrm{UCS}, \varnothing 55 \mathrm{~mm}$, static & $101 \mathrm{MPa}$ \\
$\mathrm{UCS}, \varnothing 55 \mathrm{~mm}$, hysteresis & $81.5 \mathrm{MPa}$ \\
$\mathrm{E} \tan$ & $50000 \mathrm{MPa}$ \\
\hline
\end{tabular}

Despite the dispersion, the differences between UCS determined with slow or fast loading and on large or small diameters are significant. No significant correlation was found between the values of the elastic and mechanical characteristics of the individual specimens and those of the characteristics determined through non-destructive tests; in other words, of the single specimens intended for fatigue tests and subsequently performed, nothing is known a priori except that they belong to a population of which some average characteristics are known.

\section{Tests with hysteresis cycles}

Tests with hysteresis cycles were carried out on 10 specimens with a diameter of 55 $\mathrm{mm}$ : the tests were set up so as to make the specimen undergo a succession of cycles with progressively increasing maximum stress values; in this way they present an analogy, at least formal, with cyclic fatigue tests, admitting that the fatigue failure is the result of progressive damage: in this hypothesis, the principle that a cycle carried out with a certain value of the maximum stress is equivalent to a certain number of cycles with lower stress value is implied. The objectives of the tests were: to obtain information on the stress at which the material leaves the linear elastic behavior, more accurate than those obtainable by examining $\sigma-\varepsilon$ diagrams; identify any changes in strength following the application of subsequent loading and unloading cycles; follow any changes in the elastic characteristics. The tests were carried out with a load application speed of $0.5 \mathrm{MPa} / \mathrm{s}$, the same used for conducting "static" tests, after setting 30 load levels with a minimum value of $60 \mathrm{kN}$ and a maximum of $260 \mathrm{kN}$ (the full scale value of the load being $500 \mathrm{kN}$ ).

The diagrams obtained from the individual tests, while showing considerable differences, have some elements in common:

1. the portion corresponding to the first application of the load repeats the trend known from the standard tests;

2. in the return phase from the first cycle, recovery of the strain due to the loading phase is never observed, even if the branch corresponding to unloading sometimes has a slight concavity towards the top;

3. the total strain at break was in the order of $3000 \mu \varepsilon$; it is not linked to the number of hysteresis cycles endured before failure (and therefore with the maximum stress) and varies comparatively little from specimen to specimen;

4. the maximum tolerated stress varies from a minimum of $46 \mathrm{MPa}$ to a maximum of 118 $\mathrm{MPa}$, with an average value of $81.5 \mathrm{MPa}$; 
5. in the subsequent cycles, and before the $2-3$ anomalous cycles that precede the failure, there is a tendency, in the loading branches, to a higher elastic modulus than that of the virgin sample and, generally, to a "work softening" behavior (concavity downwards) or perfectly linear;

6. the subsequent cycles chain a negligible strain work, until a "critical" cycle is reached which links a major strain work, which may show the overcoming of the elastic behavior, although this is not evident from the examination of the $\sigma-\varepsilon$ diagram. It can therefore be asserted that the failure usually takes place at a value that exceeds the elastic limit by 10-20 MPa. In the lot of samples tested, the elastic limit identified as described varies between a minimum of $35 \mathrm{MPa}$ and a maximum of $95 \mathrm{MPa}$, with an average value of around $65 \mathrm{MPa}$.

An example of a diagram obtained is given in Figure 4.

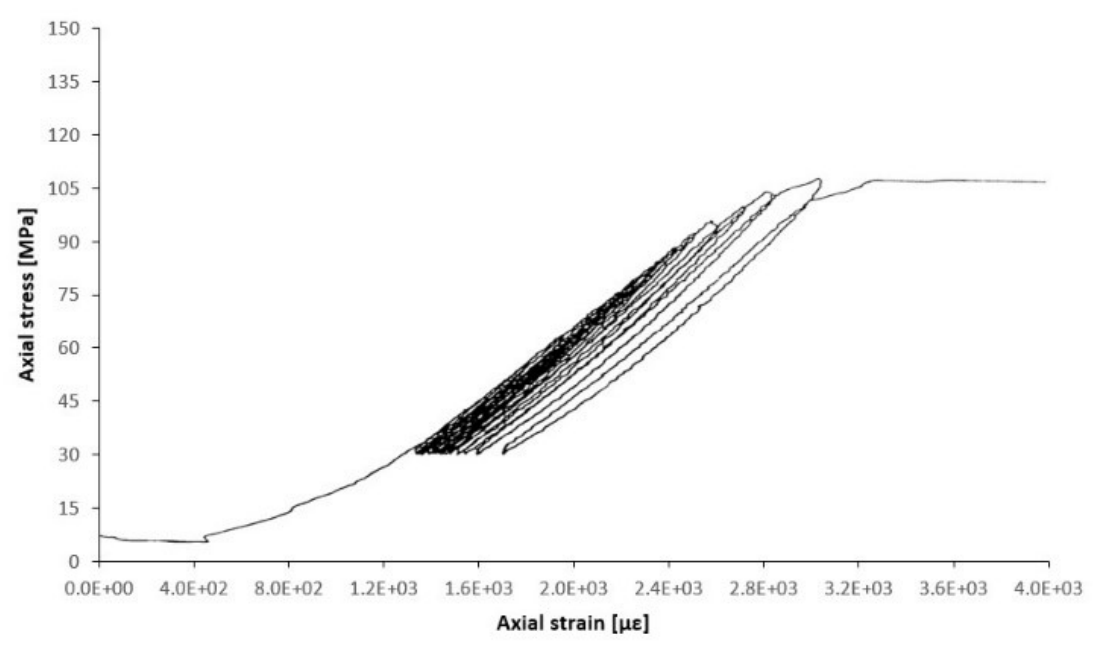

Figure 4. "Axial stress-axial strain" diagram relating to one of the specimens subjected to failure with hysteresis cycles; in particular, from the diagram it is possible to detect the variation in strain work linked to the hysteresis cycle as the maximum stress in the cycle increases.

In general, it can be said that any change requires work: the only way to extract work from a cyclic strain is to have a hysteresis loop concatenating a non-zero work. It is therefore possible to consider a particularly significant increase in the work linked to the hysteresis cycle as a prodromal of failure, regardless of any particular hypothesis on the actual causes of the failure itself. Furthermore, the trend of the work linked to the hysteresis cycle (null by definition, in the elastic range) provides an unequivocal indication of the plasticization of the material, which is an effective clue of fatigue. From the diagram in Figure 4, the values of the work linked to the hysteresis cycle shown in Figure 5 have been determined: in this regard, it can be observed that, up to the maximum stress of about 85 $\mathrm{MPa}$, the work is very small and poorly assessable: this value can therefore represent with good reliability the elastic limit of the specimen tested. The rapid increase of the hysteresis work beyond this threshold is evident, as is also evident, from the analysis of the $\sigma-\varepsilon$ graph, the rapid increase of the residual strain between the following cycles, starting from the one where the maximum stress is $85 \mathrm{MPa}$. It is recalled that the specimen's UCS was $117 \mathrm{MPa}$ and would probably have been higher if the specimen had been tested with an ordinary static test. If the fatigue limit were identified with the elastic limit, as proposed by [43], said fatigue limit would be located at $72.6 \%$ of the breaking load: in fact $(85 / 117)$ $x 100=72.6$. Other authors $[44,45,28,27]$ have subsequently confirmed this theory through experimental tests. 
The hysteresis tests with an increasing maximum stress are certainly not equivalent to fatigue tests with a constant maximum stress, nor what has been obtained from a single specimen can be extrapolated to all specimens: however, it can be admitted that the failure due to cyclic loads is preceded by an increase in the work linked to the loading and unloading cycles, i.e. that fatigue consists in a reduction of the elastic limit (not necessarily in a reduction of UCS) due to the cycles, which can derive from micro-cracks or structural changes of the material.

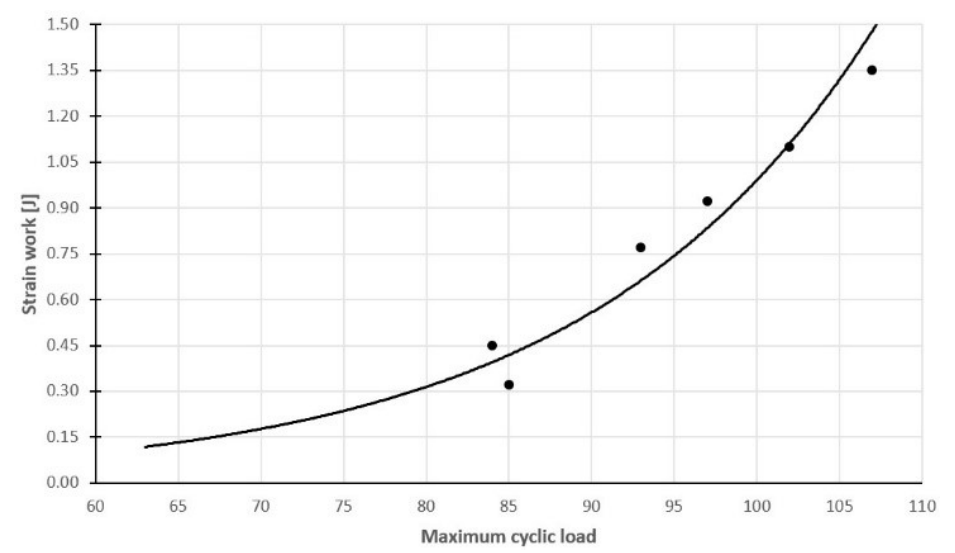

Figure 5. Trend of strain work linked to the hysteresis cycle shown in Figure 4.

However, it is to be kept in mind that the increase in the load application speed in the hysteresis tests was significantly lower than that used in the cyclic fatigue tests: this has undoubtedly allowed a more accurate detection of the $\sigma-\varepsilon$ curves, but it is necessary to remember that the two concepts (hysteresis and fatigue) are not generalizable.

\section{Cyclic fatigue tests}

The tests were carried out on 40 specimens with a diameter of $71 \mathrm{~mm}$, tested at different values of the maximum stress (corresponding to different percentages of average UCS obtained from static tests), initially limiting the maximum number of cycles to 106. The extension to values of $\sigma_{\max } / \mathrm{UCS}$ greater than $100 \%$ is justified as dynamic UCS is greater than the reference static UCS. For the execution of the tests, it was decided to operate under the conditions listed below:

1. sinusoidal waveform;

2. frequency $2 \mathrm{~Hz}$;

3. maximum load $40 \mathrm{kN}$;

4. full scale value of the load $500 \mathrm{kN}$.

It did not seem useful to explore the behavior with cyclic load lower than $50 \%$ of the average static UCS, as from the literature this value is clearly lower than the fatigue limit (Figure 3).

All the specimens that survived 106 cycles were again subjected to non-destructive tests in the same way as in the preliminary tests and, then, to further fatigue tests. The results of the non-destructive tests are given in Table 2.

In general, there is no systematic degradation of the material. The results of the UCS tests on the specimens that survived $10^{6}$ cycles are collected in Table 3, where it can be observed that the UCS values obtained on the specimens subjected to the fatigue cycles fall perfectly within the range of the values determined (with dynamic test) on virgin specimens of the same material: it is therefore plausible that fatigue does not progress at a constant rate from the beginning of the test. By referring, instead, to the average UCS 
value determined with static test on the reference batch $(73.5 \mathrm{MPa})$, an apparent improvement in the mechanical characteristics is noticeable: it is however to consider the hypothesis that those specimens, having exceeded $10^{6}$ cycles, were mechanically better than the average. In any case, the failure, precursor of the breakage, which must necessarily subsist and which is visually observed following the evolution of the test, is a relatively sudden phenomenon.

Table 2. Results of non-destructive tests on specimens that survived 106 cycles.

\begin{tabular}{|c|c|c|c|c|c|}
\hline \multirow[t]{2}{*}{$\begin{array}{c}\text { Sample n. } \\
(-)\end{array}$} & \multirow[t]{2}{*}{$\begin{array}{c}\sigma_{\max } / \mathrm{UCS} \\
(\%)\end{array}$} & \multicolumn{2}{|c|}{$\begin{array}{l}\text { Speed of longitudinal elastic waves } \\
\qquad(\mathrm{m} / \mathrm{s})\end{array}$} & \multicolumn{2}{|c|}{$\begin{array}{c}\text { Imbibition coefficient } \\
(-)\end{array}$} \\
\hline & & Initial & After $10^{6}$ cycles & Initial & After $10^{6}$ cycles \\
\hline 30 & 50 & 5488.46 & 5285.18 & 0.0007 & 0.0009 \\
\hline 29 & 60 & 5552.50 & 5563.35 & 0.0009 & 0.0010 \\
\hline 4 & 50 & 4960.72 & 4663.39 & 0.0009 & 0.0009 \\
\hline 2 & 70 & 5508.03 & 5246.32 & 0.0004 & 0.0005 \\
\hline 34 & 60 & 5221.37 & 5227.10 & 0.0007 & 0.0007 \\
\hline 41 & 90 & 6064.59 & 5970.71 & 0.0003 & 0.0005 \\
\hline 16 & 90 & 5477.93 & 5344.57 & 0.0005 & 0.0011 \\
\hline 19 & 80 & 5334.58 & 5246.32 & 0.0007 & 0.0010 \\
\hline 50 & 70 & 5015.82 & 5060.88 & 0.0008 & 0.0009 \\
\hline
\end{tabular}

The samples, subjected to further fatigue and then broken for further cycles of fatigue, gave the results of Table 4: apart from the last, probably due to some undetectable change during the test (e.g. effect of non-destructive tests, small modification of the specimen centering when loaded) but which indirectly signals the "catastrophic" character of the failure, the others followed a behavior similar to that of specimens that have not undergone previous fatigue cycles.

Table 3. Results of UCS tests on specimens that survived $10^{6}$ cycles, with indication of the additional cycles supported.

\begin{tabular}{cccc}
\hline $\begin{array}{c}\text { Sample }^{\circ} \\
(-)\end{array}$ & $\begin{array}{c}\boldsymbol{\sigma}_{\max } / \mathrm{UCS} \\
(\mathbf{\%})\end{array}$ & $\begin{array}{c}\text { UCS } \\
(\mathbf{M P a})\end{array}$ & $\begin{array}{c}\text { Total number of cy- } \\
\text { cles supported be- } \\
\text { fore the static test }\end{array}$ \\
\hline 4 & 50 & 99.43 & $10^{6}+101$ \\
30 & 50 & 96.96 & $10^{6}+13600$ \\
29 & 60 & 88.27 & $10^{6}+1030000$ \\
34 & 60 & 96.71 & $10^{6}+49000$ \\
2 & 70 & 98.44 & $10^{6}+1187000$ \\
\hline
\end{tabular}

Table 4. Additional cycles endured before fatigue failure from specimens surviving $10^{6}$ cycles.

\begin{tabular}{ccc}
\hline $\begin{array}{c}\text { Sample } \mathbf{n}^{\circ} \\
(-)\end{array}$ & $\begin{array}{c}\boldsymbol{\sigma}_{\max } / \mathrm{UCS} \\
(\mathbf{\%})\end{array}$ & $\begin{array}{c}\text { Additional cycles endured } \\
(-)\end{array}$ \\
\hline 50 & 70 & 373022 \\
19 & 80 & 18471 \\
16 & 90 & 296257 \\
41 & 90 & 135 \\
\hline
\end{tabular}


For a correct interpretation of the results, it should be noted that the number of cycles necessary to reach failure is apparently never reduced to one, as it has been found that the recording apparatus continues recording load cycles after the failure has occurred, until the displacement of the press plate has reached its full scale value, equal to $50 \mathrm{~mm}$. A load cycle, in particular, lasts $0.5 \mathrm{~s}$ and it has been found that recording stops 5-10 s after the actual breakage; the life of the specimen is therefore unduly extended by about 15 cycles. This inaccuracy does not cause inconvenience in tests where the breakage occurs after hundreds or thousands of cycles, but must be considered in cases where it occurs after a few cycles: therefore, the mentioned fact has been taken into account by reducing the number of cycles recorded before the breakage. The correct values are shown in Table 5 . The table also shows that up to the value of $\sigma_{\max } / \mathrm{UCS}_{\text {average }} \geq 0.95\left(\sigma_{\max } \geq 69.8 \mathrm{MPa}\right)$ no samples passed $10^{6}$ cycles; when $\sigma_{\max } / \mathrm{UCS}_{\text {average }}=0.9\left(\sigma_{\max }=66.15 \mathrm{MPa}\right)$ two out of five samples have passed $10^{6}$ cycles and, for lower loads, all specimens passed $10^{6}$ cycles. If the value of $10^{6}$ cycles were conventionally adopted as indicative of the fatigue limit, these data suggest that this limit would be around $60 \mathrm{MPa}$.

Table 5. Number of cycles at breakage found on the 40 fatigue-stressed specimens, with indication of the maximum stress reached.

\begin{tabular}{cccc}
\hline $\begin{array}{c}\text { Sample tested } \mathbf{n}^{\circ} \\
(-)\end{array}$ & $\begin{array}{c}\boldsymbol{\sigma}_{\max } / \mathbf{U C S} \\
(\%)\end{array}$ & $\begin{array}{c}\boldsymbol{\sigma}_{\max } \\
(\mathbf{M P a})\end{array}$ & $\begin{array}{c}\text { Number of cycles (correct) } \\
(-)\end{array}$ \\
\hline 2 & 50 & 36.75 & $>106,>106$ \\
2 & 60 & 44.1 & $>106,>106$ \\
2 & 70 & 51.45 & $>106,>106$ \\
1 & 80 & 58.8 & $>106$ \\
5 & 90 & 66.15 & $>106,>106,24421,1820,236$ \\
5 & 95 & 69.8 & $594975,242492,8792,287,154$ \\
5 & 100 & 73.5 & $1550,479,147,39,6$ \\
5 & 110 & 80.8 & $51962,1710,209,32,3$ \\
5 & 115 & 84.5 & $218,204,194,105,1$ \\
5 & 120 & 88.2 & $81,186,46,10,6$ \\
3 & 130 & 95.5 & $50,8,8$ \\
\hline
\end{tabular}

The results of the fatigue tests are generally reported in a diagram that has the number of cycles on the horizontal (logarithmic) axis, and the corresponding maximum stress on the vertical (linear) axis. As an example of this representation method, Figure 6 shows a diagram taken from a study by [46], which summarizes the results of fatigue tests (over $6 \times 10^{6}$ cycles) on samples made of aluminium alloys. The fatigue curve includes 2 distinct parts: on the left, the trend is steeply sloping, which implies that the fatigue strength decreases rapidly as the number of cycles increases; on the right, it is almost parallel to the horizontal axis: in fact, if the maximum stress does not exceed a certain magnitude (in the case in question, variable from 75 to $90 \mathrm{MPa}$ for the three different alloys) the samples could overcome the fatigue for a number of cycles tending to infinity, without failure occurring (the corresponding load is called the "fatigue limit" of the material).

If the points relating to the experimental tests on the limestone examined are reported in a similar diagram (Figure 7), a well-defined correlation is not obtained like that of the quoted example but, despite the small number of tests and the uncertainty associated with of the results, a useful representation to roughly define the behavior of the material is obtained. 


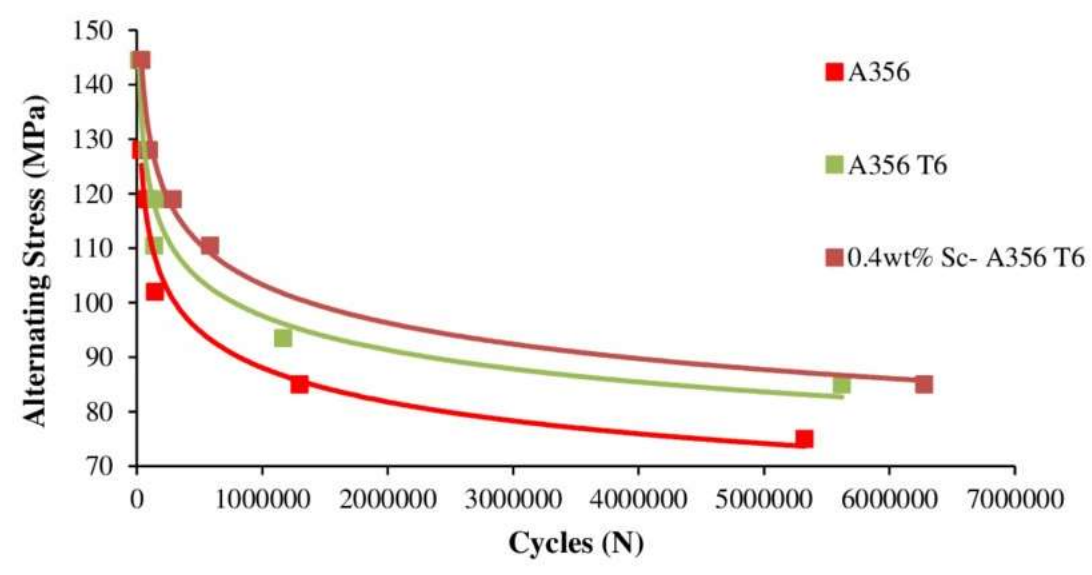

Figure 6. S-N Curve of A356, A356-T6 heat treated and 0.4wt\% Sc-A356-T6 heat treated aluminium alloy (Masita et al., 2018).

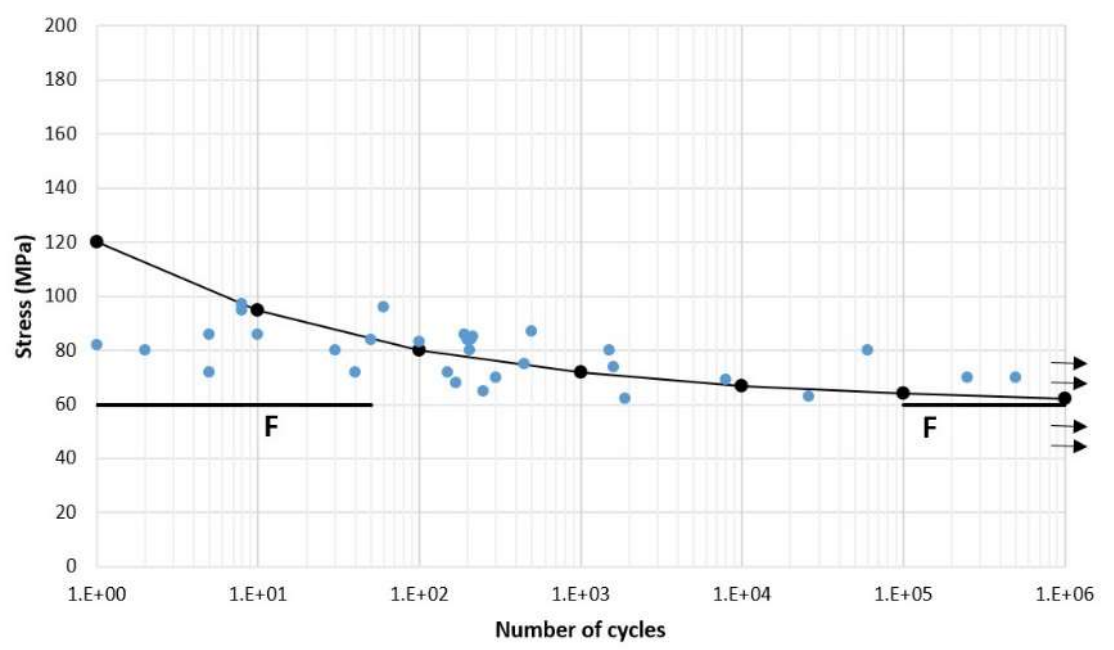

Figure 7. S / N curve, with indication of the experimental points, corresponding to the probability of survival equal to $50 \%$.

\subsection{Interpretation of the results}

In the $\mathrm{S} / \mathrm{N}$ plan (or $\mathrm{S} / \log \mathrm{N}$ adopted in this case for convenience) a swarm of points indicating a correlation that can be variously understood is obtained. Based on a visual examination of the distribution of the points it can be postulated, for the mathematical expression of this correlation, an asymptote, having a maximum value corresponding to the single cycle and a decreasing monotone trend. For the analytical form of this correlation, the following expression (already proposed by Weibull for the representation of the fatigue behavior of metals and widely used) can be adopted:

$$
\mathrm{P}(\mathrm{S}-\mathrm{F})^{\mathrm{K}} \times \mathrm{N}=\mathrm{C}
$$

where $\mathrm{S}$ is the maximum stress of the cycle, $\mathrm{F}$ the fatigue limit, $\mathrm{N}$ the number of cycles at breakage, $\mathrm{K}$ and $\mathrm{C}$ two experimental constants. The expression is simple and flexible, being controlled by three parameters (F, K, C) that define the material; to search for the most suitable values of these parameters, the expression can be written in the form:

$$
\log (\mathrm{S}-\mathrm{F})=\mathrm{A}-\mathrm{B} \log \mathrm{N}
$$


where $A=\log (C / K), B=1 / K$, which is linear in $\log (S-F)$ and in $\log N$ and could be used to determine the most suitable values of $A$ and $B$ (therefore of $C$ and $K$ ) with a linear regression using the available data. However, the most suitable value of $\mathrm{F}$, which is not known a priori, must also be determined. Therefore:

1. attempt values close to the estimated asymptote were assigned to $\mathrm{F}$, roughly suggested by the distribution of the experimental points;

2. for each value of $\mathrm{F}$ the values of $\mathrm{A}$ and $\mathrm{B}$ were searched through a linear regression between $\log (\mathrm{S}-\mathrm{F})$ and $\log \mathrm{N}$, and the relative correlation coefficient was calculated;

3. the three values of A, B, F for which this coefficient resulted maximum have been assumed as the most suitable.

Before presenting the results, the possible meanings of the analytical expression are examined. First of all, it is observed that for $\mathrm{N}=1(\log N=0)$ the experimental curve sought is significantly above the static UCS value: this means that, in order to detect a normalized experimental relationship $\mathrm{S} / \mathrm{N}$, it is necessary to assume as the reference strength a higher value than that determined by static tests (since the strength determined with a rapid load application is higher than that determined with slow application). Furthermore, it is important to deduce the meaning of the material's behavior: the normalized S/N curve of a hypothetical average material can be obtained, i.e. postulating a valid $\mathrm{S} / \mathrm{N}$ relationship for that material, up to a scale factor represented by the single cycle strength of each specimen (a priori not known), or postulating a relationship that divides, in the S/N Cartesian plane, the conditions (load-number of cycles) that ensure certain survival probability values (or failure) for the material: for the purpose of its description, the attention can be fixed on the $50 \%$ probability of survival.

In the first hypothesis, the regressions will be performed on the average values of the number of cycles at breakage found at the different values of the maximum load in the cycle, in the second on the median values, i.e. on the number of cycles (for each value of the maximum load in the cycle) at which survival occurred in half of the cases. The available data are shown in Table 6.

The regression on the mean values leads to the expression:

$$
\log (\mathrm{S}-69.55)=2.10144-0.43820 \log \mathrm{N}
$$

with a correlation coefficient of 0.839 .

Table 6. Average and median values of the number of cycles to failure for each value of the maximum stress.

\begin{tabular}{cccc}
\hline $\begin{array}{c}\boldsymbol{\sigma}_{\max } / \mathbf{U C S}_{\text {average }} \\
(\mathbf{\%})\end{array}$ & $\begin{array}{c}\boldsymbol{\sigma}_{\max } \\
\mathbf{( M P a )}\end{array}$ & $\begin{array}{c}\text { N average } \\
\mathbf{( - )}\end{array}$ & $\begin{array}{c}\text { N median } \\
\mathbf{( - )}\end{array}$ \\
\hline$<90$ & $<66.5$ & $>10^{6}$ & $>10^{6}$ \\
90 & 66.15 & 464568 & 24421 \\
95 & 69.8 & 169160 & 8792 \\
100 & 73.5 & 444 & 147 \\
110 & 80.8 & 10938 & 209 \\
115 & 84.5 & 144 & 194 \\
120 & 88.2 & 146 & 46 \\
130 & 95.5 & 22 & 8 \\
\hline
\end{tabular}

Apart from the low value of this coefficient, the expression does not seem to reasonably approximate the hypothetical "average material" (for example, the failure in the first cycle would occur at 195.8 MPa, a value that falls significantly above the observed range). Provided it is feasible, the approach would require an enormously greater amount of data 
to obtain a reliable expression (and, once obtained, it would remain unusable without a precise non-destructive procedure to know the strength of the individual samples).

The regression on the median values leads to the expression:

$$
\log \left(\sigma_{\max }-61 \mathrm{MPa}\right)=1.7676-0.2252 \log \mathrm{N}
$$

with a correlation coefficient of 0.939 .

This expression, qualitatively, satisfactorily approximates the relationship between the maximum stress and the number of cycles corresponding to $50 \%$ survival (or failure) and is the one shown in Figure 7. Notice that the value of $61 \mathrm{MPa}$ found does not represent a fatigue limit in the usual sense, but rather a maximum load that can be endured an infinite number of times in 50\% of cases. For survival values other than $50 \%$, similar expressions of the $\mathrm{S} / \mathrm{N}$ relationship could be obtained in the same way, provided however that a greater amount of experimental data is available.

\section{Conclusions}

Even with the same maximum load in the cycle it was found that the failure occurs after a very variable number of cycles: from case to case the dispersion is often several orders of magnitude.

No measurable characteristic is able to distinguish the specimens that evolve towards a rapid failure from those that withstand for tens or hundreds of thousands cycles, yet some difference is observable after the test, for how the failure occurred: the specimens that endure longer tend to provide a finer debris, as if the prolonged repetition of the cycles had, in some way, made the rock more "crumbly". The observed effect, documented in the graphs of Figure 8, is not a consequence of the random dispersions of the particle size of the debris, but is statistically significant.

Therefore, there is a progressive degradation of the rock structure due to the cyclic load, which can be imagined as slow and gradual; but there is also the chance that the failure develops quickly, before the compactness of the mass has suffered from this effect. The global behavior of the lot of specimens seems to respect a rather complex model: progressive and non-localized damage, which is superimposed, in a certain instant dictated by chance, by the catastrophic enlargement of one or a few "significant" micro-lesions. The term "chance" is used here to emphasize the fact that the instant in which the catastrophic event occurs does not depend on a particular characteristic of the material, but on the individual specimen.

In summary, the nature and modalities of failure under cyclic loading remain unclear; many authors in fact state that the type of failure is different based on the type of load applied [8, 47, 41,45], although others claim no discrepancies in the broken specimens [48]. The thesis supported is that probably the type of fracture depends on the brittleness characteristics of the rock examined. Another possible explanation is that the low-frequency cyclic loading allows the initiation, nucleation and localization of tensile cracks that grow parallel to the loading axis during the loading-unloading phases; under monotonous loading and high frequency cyclic loading, the tensile cracks do not have sufficient time to develop, so propagation and final failure occur along two shear planes that join in the central area of the sample [40]. Regarding the low frequency cyclic failure, this allows the development of microcracks that propagate progressively [41]. 


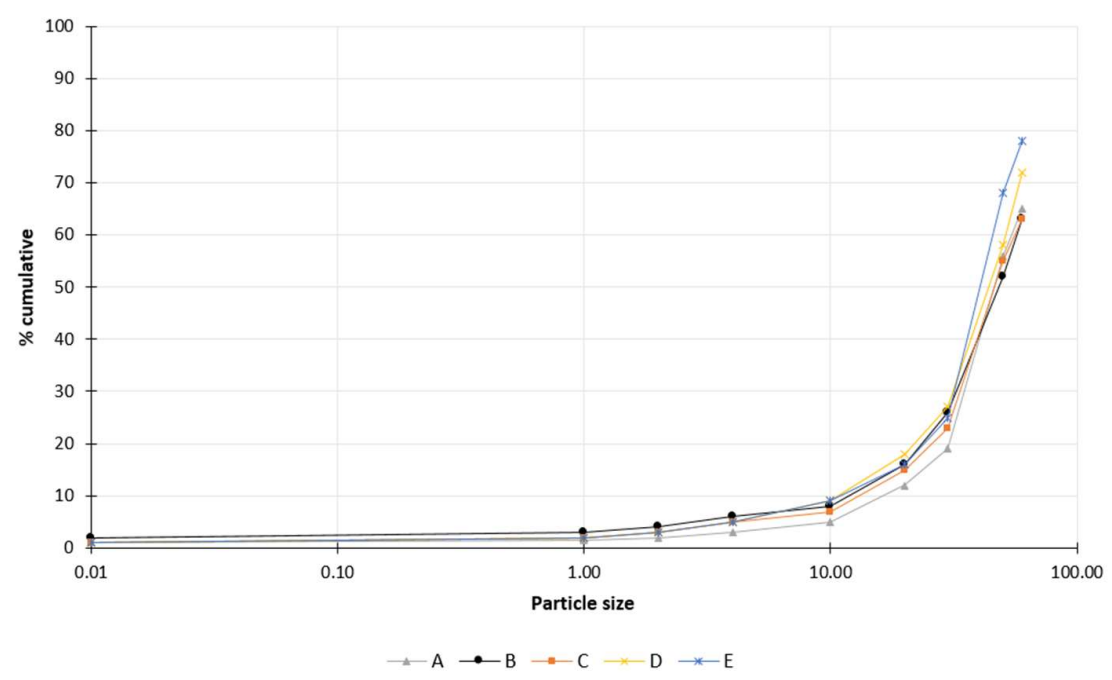

Figure 8. Diagram of the average particle size distributions obtained with round-hole sieves on the fragments of $71 \mathrm{~mm}$ diameter specimens broken during the static tests (A), the dynamic tests (B), the fatigue tests with less than 100 cycles (C), the fatigue tests after 100-1000 cycles (D) and beyond 10,000 cycles (E). On the vertical axis: cumulative passing $\%$.

However, it seems clear that the material is best described by means of a survival curve. This model, which leads to the superposition of a deterministic chain of events on a localized and random triggering event, also allows for a re-composition of the two contrasting points of view presented by Scholz [49-51] and Cruden [52,53] regarding the phenomenon, in many respects similar to that of cyclic fatigue, of "creep": the first traces the failure to the progressive increase in the density of micro-cracks, until reaching a "critical density" of these defects, the second to the progressive increase in the length of some micro-lesions, up to the overcoming, in some point, of the critical Griffith "length" [54]. Basically, in Cruden's work, Scholz's theory of brittle creep is rejected.

In fact, it seems plausible that, in the case of cyclical fatigue of rocks, the two failure mechanisms chase each other in a race in which chance is the arbiter: if the second mechanism arises earlier, there is the "oligocyclic" fatigue that gives rise to a debris similar to that obtainable with normal static tests (and in fact in this case the phenomenon is the same, apart from a slight dilution over time); if instead it arises late, a material develops that is no longer, micro-mechanically speaking, the starting material, but is already marked by a real "fatigue phenomenon", so that the "polycyclic" fatigue occurs.

Funding: This research received no external funding.

Conflicts of Interest: The authors declare no conflict of interest. 


\section{References}

1. Miner, M. Cumulative damage in fatigue. J Appl Mech 1945, 12(3), 159-164.

2. Tóth, L.; Yarema, S. Ya. Formation of the science of fatigue of metals. Part 1. 1825-1870. Mater Sci 2006, 42, 673-680.

3. Marines, I.; Bin, X.; Bathias, C. An understanding of very high cycle fatigue of metals. Int J Fatigue 2003, 25(9-11), 1101-1107.

4. Abel, A.; Muir, H. The Bauschinger effect and stacking fault energy. Philos Mag: J Theor Exp Appl Phys 1973, 27(3).

5. Moore, H.E.; Kommers, J.B. The fatigue of metals. McGraw Hill Book Company, New York, 1927, pp. 77-80.

6. Brown, E.; Hudson, J. Fatigue failure characteristics of some models of jointed rocks. Earthq Eng Struct Dyn 1974, 2, 379-386.

7. Rajaram, V. Mechanical behavior of granite under cyclic compression. In: First international conference on recent advances in geotechnical earthquake engineering. 1981.

8. Burdine, N. Rock failure under dynamic loading conditions. Soc Petrol Eng J 1963, 3(01), 1-8.

9. Atkinson, B. Subcritical crack growth in geological materials. J Geophys Res 1984, 89(B6), 4077. doi:10.1029/JB089iB06p04077.

10. Attewell, P.; Farmer, W. Fatigue behaviour of rock. Int J Rock Mech Min Sci 1973, 10, 1-9.

11. Kumar, A. The effect of stress rate and temperature on the strength of basalt and granite. Geophys 1968, 33(3), 501-510.

12. Kranz, R.L. Microcracks in rocks: a review. Tectonophysics 1983, 100(1-3), 449-480. doi:10.1016/0040-1951(83)90198-1

13. Attewell, P.; Sandford, M. Intrinsic shear strength of a brittle, anisotropic rock: experimental and mechanical interpretation. Int J Rock Mech Min Sci Geomech Abstr 1974, 11(11), 423-430.

14. Costin, L. S.; Holcomb, D. J. Time-dependent failure of rock under cyclic loading. Tectonophysics 1981, 79(3-4), 279-296. doi:10.1016/0040-1951(81)90117-7.

15. Evans, A.; Fuller, R. Crack propagation in ceramic materials under cyclic loading conditions. Metall Trans 1974, 5, 27-33.

16. Alarcon-Guzman, A.; Leonards, G.; Chameau, J. Undrained monotonic and cyclic strength of sand. J Geotech Eng 1989, 114(10), 1089-1109.

17. Fan, J.; Chen, J.; Jiang, D.; Chemenda, A.; Chen, J.; Ambre, J. Discontinuous cyclic loading tests of salt with acoustic emission monitoring. Int J Fatigue 2017, 94, 140-144. doi:10.1016/j.ijfatigue.2016.09.016.

18. Fan, J.; Chen, J.; Jiang, D.; Ren, S.; Wu, J. Fatigue properties of rock salt subjected to interval cyclic pressure. Int J Fatigue 2016, 90, 109-115.

19. Fuenkajorn, K.; Phueakphum, D. Effects of cyclic loading on mechanical properties of Maha Sarakham salt. Eng Geol 2010, 112(14), 43-52.

20. Cerfontaine, B.; Collin, F. Cyclic and Fatigue Behaviour of Rock Materials: Review, Interpretation and Research Perspectives. Rock Mech Rock Eng 2018, 51, 391-414.

21. Chow, T. M.; Meglis, I. L.; Young, R.P. Progressive microcrack development in tests on Lac du Bonnet granite-II. Ultrasonic tomographic imaging. Int J Rock Mech Min Sci 1995, 32(8), 751-761.

22. Dowling, N.E. Crack growth during low cycle fatigue of smooth axial specimens. Proceedings of the Int. Conf. on "Cyclic stressstrain and plastic deformation aspects of fatigue crack growth", ASTM Special Technical Publication 637, American Society for testing and materials, Philadelphia, 1977, Pa. 19103.

23. Weibull W. A Statistical Distribution Function of Wide Applicability. J Appl Mech 1951, 18, $293-297$.

24. Liu, Y.; Deng, L.; Zhong, W.; Xu, J.; Xiong, W. A new fatigue reliability analysis method for steel bridges based on peridynamic theory. Eng Fract Mech 2020, 236, 107214.

25. Ishizuka, Y.; Abe, T.; Kodama, J. Fatigue behaviour of granite under cyclic loading. Proceedings of the SRM International Symposium, Mbabane, Swaziland, September 1990; Balkema: Rotterdam, pp. 139-146.

26. Bagde, M.N.; Petros, V. Fatigue properties of intact sandstone samples subjected to dynamic uniaxial cyclical loading. Int J Rock Mech Min Sci 2005, 42(2), 237-250.

27. He, M.; Huang, B.; Zhu, C.; Chen, Y.; Li, N. Energy dissipation-based method for fatigue life prediction of rock salt. Rock Mech Rock Eng 2018, 51, 1447-1455.

28. Vaneghi, R.; Ferdosi, B.; Okoth, A.D.; Kuek, B. Strength degradation of sandstone and granodiorite under uniaxial cyclic loading. J Rock Mech Geotech Eng 2018, 10(1), 117-126.

29. Yang, B.; Liaw, P.K.; Wang, G.; Morrison, M.; Liu, C.T.; Bauchanan, R.A.; Yokoyama, Y. In-situ thermographic observation of mechanical damage in bulk-metallic glasses during fatigue and tensile experiments. Intermetallics 2004, 12(10-11), 1265-1274.

30. Fleck, N.; Shin, C.; Smith, R. A. Fatigue Crack Growth Under Compressive Loading. Eng Fract Mech 1985, 21(1), $173-185$.

31. Singh, S. Fatigue and Strain Hardening Behaviour of Graywacke from the Flagstaff Formation, New South Wales. Eng Geol 1989, 26(2), 171-179.

32. Ray, S.; Sarkar, M.; Singh, T. Effect of Cyclic Loading and Strain Rate on the Mechanical Behaviour of Sandstone. Int J Rock Mech Min Sci 1999, 36(4), 543-549.

33. Erarslan, N.; Williams, D.J. The damage mechanism of rock fatigue and its relationship to the fracture toughness of rocks. Int J Rock Mech and Mion Sci 2012, 56, 15-26.

34. Song, R.; Yue-ming, B.; Jing-Peng, Z.; De-yi, J.; Chun-he, Y. Experimental Investigation of the Fatigue Properties of Salt Rock. Int J Rock Mech Min Sci 2013, 64, 68-72.

35. Nejati, H.R.; Ghazvinian, A. Brittleness Effect on Rock Fatigue Damage Evolution. Rock Mech Rock Eng 2014, 47, $1839-1848$.

36. Jia, H.; Xiang, W.; Krautblatter, M. Quantifying Rock Fatigue and Decreasing Compressive and Tensile Strength after Repeated Freeze-Thaw Cycles. Permafrost and Periglacial Processes 2015, 26(4), 368-377. 
37. Jamali, S.; Hashemolhosseini, H.; Baghbanan, A.; Khoshkam, M.; Haghgouei, H. Evaluating Fatigue in Crystalline Intact Rocks under Completely Reversed Loading. Geotech Test J 2017, 40(5), 789-797.

38. Phueakphum, D.; Fuenkajorn, K. Effects of Cyclic Loading on Mechanical Properties of Maha Sarakham Salt. Proceeding of the Second Thailand Symposium, Rock Mechanics, Chonburi, Thailand, 2009 Institute of Engineering, Suranaree University of Technology, pp. 107-120.

39. Vaneghi, R.; Thoeni, K.; Dyskin, A.V.; Sharifzadeh, M. Strength and Damage Response of Sandstone and Granodiorite under Different Loading Conditions of Multistage Uniaxial Cyclic Compression. Int. J. Geomech 2020a, 20(9), 1-19.

40. Vaneghi, R.; Thoeni, K.; Dyskin, A.V.; Sharifzadeh, M.; Sarmadivaleh, M. Fatigue damage response of typical crystalline and granular rocks to uniaxial cyclic compression. Int J Fatigue 2020b, 138, 1-13.

41. Guo, Y.; Yang, C.; Wang, L.; Xu, F. Effects of Cyclic Loading on the Mechanical Properties of Mature Bedding Shale. Adv Civ Eng 2018, Special Issue on "Damage and Fracture Behaviour of Rock", 2018, Article ID 8985973, 9 pages.

42. Ulusay, R.; Hudson, J. A. The Complete ISRM Suggested Methods for Rock Characterization, Testing and Monitoring: 1974-2006. ISRM, 2007

43. Attewell, P.B.; Farmer, I.W. Attenuation of Ground Vibrations from Pile Driving. Ground Eng 1973, 6, $26-29$.

44. Singh, S.P. Fatigue Strength of Hybrid Steel-Polypropylene Fibrous Concrete Beams in Flexure. Procedia Eng 2011, 14, 24462452.

45. Thaeri, A.; Royle, A.; Yang, Z.; Zhao, Y. Study on variations of peak strength of a sandstone during cyclic loading. Geomech Geophys Geo-energ Geo-resour 2016, 2, 1-10.

46. Masita, A.; Yeo, W.H.; Saw, L.H.; Lim, Y.P.; Lee, J.W.; Ng, T.C. Mechanical and Fatigue Properties of Gravity Die-Cast A356 Aluminium Alloy with Addition of Scandium. Proceedings of the International Conference on Sustainable Energy and Green Technology, IOP Conference Series: Earth and Environmental Science 2018, pp. 1-5.

47. Royer-Carfagni, G.; Salvatore, W. The characterization of marble by cyclic compression loading: experimental results. Mech Cohesive-Frict Mater 2000, 5(7), 535-563.

48. Liu, Y.; Dong, L.; Xu, N.; Feng, P. Experimental Investigation on the Fatigue Mechanical Properties of Intermittently Jointed Rock Models Under Cyclic Uniaxial Compression with Different Loading Parameters. Rock Mech Rock Eng 2018, 51, 47-68

49. Scholz C.H. Microfracturing and the inelastic deformation of rock in compression. J Geophys Res 1968a, 73, 1417-1432.

50. Scholz C.H. Mechanism of creep in brittle rock. J Geophys Res 1968b, 73, 3295-3302.

51. Scholz C.H. Experimental study of the fracturing process in brittle rock. J Geophys Res 1968c, 73, 1447-1454.

52. Cruden, D. M. The static fatigue of brittle rock under uniaxial compression. Int J Rock Mech Min Sci Geomech Abstr 1974, 11(2), 67-73.

53. Cruden D.M. A theory of brittle creep in rock under uniaxial compression. J Geophys Res 1970, 75(17) 3431-3442.

54. Griffith A.A. The theory of rupture. Proceeding of the International Congress Applied Mechanics, 1924, Delft (quoted by Palat P. Mécanisme de la propagation d'une fissure, Révue de L'industrie Minerale-Mines, 1971, 46-55). 